\title{
Jugular Foramen Schwannoma
}

National Cancer Institute

\section{Source}

National Cancer Institute. Jugular Foramen Schwannoma. NCI Thesaurus. Code C5323.

A rare intracranial schwannoma that affects the jugular foramen. 